Int. J. Morphol.,

36(1):80-86, 2018.

\title{
The Presence of Lingual Foramina and Canals on CBCT on Patients over 18 Years of Age
}

\author{
Presencia en el CBCT de Foraminas y Canales Linguales \\ en Pacientes Mayores de 18 Años de Edad
}

Álvaro Sanhueza'; Michelle Briner²; Magdalena Calvo³ \& Alejandra Cisternas ${ }^{4}$

SANHUEZA, A.; BRINER, M.; CALVO, M. \& CISTERNAS, A. The presence of lingual foramina and canals on CBCT on patients over 18 years of age. Int. J. Morphol., 36(1):80-86, 2018.

SUMMARY: Lingual foramina and canals are located in the midline of the jaw, which are important due to their neurovascular content. The location of the lingual foramina and canals can be classified according to their relationship to the mental spines; upper, middle or lower. The objective of the study was to determine the prevalence, size and anatomic location of the lingual foramina and canals and in patients older than 18 years of age that were patients at the Universidad de Los Andes, Dentistry Clinic, San Bernardo, Santiago, Chile. Furthermore, to establish sex differences regarding the presence, location and diameter of lingual foramina. From the sample total, 296 foramina were found, from which 133 (45\%) were upper foramina, 43 (15\%) middle foramina and 120 (40\%) lower foramina. In both sexes the prevalence of upper foramina was higher. Regarding the vertical diameter of the foramina, the median of the upper foramina was $0.76 \mathrm{~mm}$, the median of the middle foramina was $0.52 \mathrm{~mm}$ and the median of the lower foramina was $0.55 \mathrm{~mm}$. As for the length of the lingual canals, the middle canal was the largest $(7.48 \mathrm{~mm})$, followed by the upper $(7.53 \mathrm{~mm})$ and the lower $(6.83$ $\mathrm{mm}$ ). There was no statistically significant difference between sexes regarding the amount and size of the lingual foramina, neither regarding the size and age of the patients, but there was a difference between the lengths of the canals, being the male patients the ones that presented longer canals in the 3 different kinds. Because of the high prevalence of foramina and canals in the sample, it is recommended to consider them in the planning of surgical procedures on the mandible midline.

KEY WORDS: Cone Beam Computed Tomography; Lingual foramina; Mandible midline.

\section{INTRODUCTION}

The presence and clinical significance of lingual foramina and their respective lingual canals in the jawbone have been well established, since they contain arteries and nerves. All surgical procedures on the anterior area of the mandible body, such as the installation of implants, genioplasty, deepening of the lingual flank surgery, fractures, among others, may present complications when invading vascular structures, causing hemorrhage and sublingual hematoma. These may even be life threatening for the patient (Miller et al., 2011; Soto et al., 2012).

Different post-surgical alteration have occurred due to the perforation of these foramina, followed by an hematoma in the sublingual region and the consequent elevation of the mouth floor and tongue, leading to an obstruction of the respiratory tract (Rosano et al., 2009; Patil et al., 2013).
As reported in the scientific literature, the lingual foramina are orifices located in the mandibular symphysis, superior and inferior to the mental spines (Murlimanju et al., 2012; Patil et al.). We can classify them in three different categories according to their location from the mental spines: upper foramina if they are on top of the mental spines, middle foramina if they are located at the same level to these spines and lower foramina if the location is below the mental spines (Tagaya et al., 2009). Usually, the number of lingual foramina is in a range from 1 to 3 , but there may be cases in which there are none (Liang et al., 2005).

As patients get older, the presence of lingual foramina is even more prevalent. This was the result of the analysis of 300 images obtained by computed tomography, where 200 subjects presented foramina. These 200 individuals were

\footnotetext{
${ }^{1}$ Oral and maxillofacial radiologist, Universidad del Desarrollo, Chile.

${ }^{2}$ General Dentist, Universidad de Los Andes, Chile.

${ }^{3}$ Oral and Maxillofacial Radiologist, Universidad de Chile, Chile.

${ }^{4}$ Oral and Maxillofacial Radiologist, Universidad de Los Andes, Chile.
} 
divided according to their age, with the following results: foramina were found in 3 subjects under 20 years of age, 39 subjects between 20-39 years old, 85 subjects between 40-59 years old and 73 subjects older than 60 years. This suggests that the presence of foramina increases with age (Patil et al.).

As for its diameter, the average size for the upper and lower lingual foramina is $0.9 \mathrm{~mm}$ and $0.8 \mathrm{~mm}$, respectively (Tagaya et al.).

The requirements for complex surgical procedures nowadays, increase the need for more specific radiographic techniques in order to analyze the normal anatomic structures and their variations.

The CBCT is a contemporary image system designed to be used in the maxillofacial region. The system exceeds the limitations of conventional radiography by producing non-distorted images of the examined area in three dimensions. Unlike conventional Computed Tomography, CBCT uses a divergent or cone shaped source of ionizing radiation and an area detector fixed on a rotating gantry to provide multiple transmission images that will come together to form a 3D image (Dreiseidler et al., 2009).

The general objective of this study is to determine the presence and amount of lingual foramina and canals using CBCT on patients over 18 years of age, treated at the Universidad de los Andes Dentistry Clinic, San Bernardo,
Santiago, Chile, between the years 2013 and 2014. The specific objectives were:

- To determine the diameter and length of the lingual foramina with their corresponding canals.

- To settle the anatomical relation between the lingual foramina and the mental spines.

- To establish the differences in sexes regarding the presence of foramina and lingual canals, and their location and diameter.

\section{MATERIAL AND METHOD}

A cross-sectional descriptive study was conducted, in which CBCT exams were observed in a computer with an Intel Core 173770 CPU, with magnification when it was considered necessary, obtained from the radiological database of the Universidad de los Andes Dentistry Clinic, San Bernardo, Santiago, Chile. The exams belonged to patients over 18 years old, which were done between August 2013 and September 2014.

The images were observed on a View Sonic VA2248m monitor, in which the Galileo® software reconstructed de images in a panoramic view, 3D reconstruction and views in 3 dimensions (tangential, transverse and axial) as shown in Fig. 1.

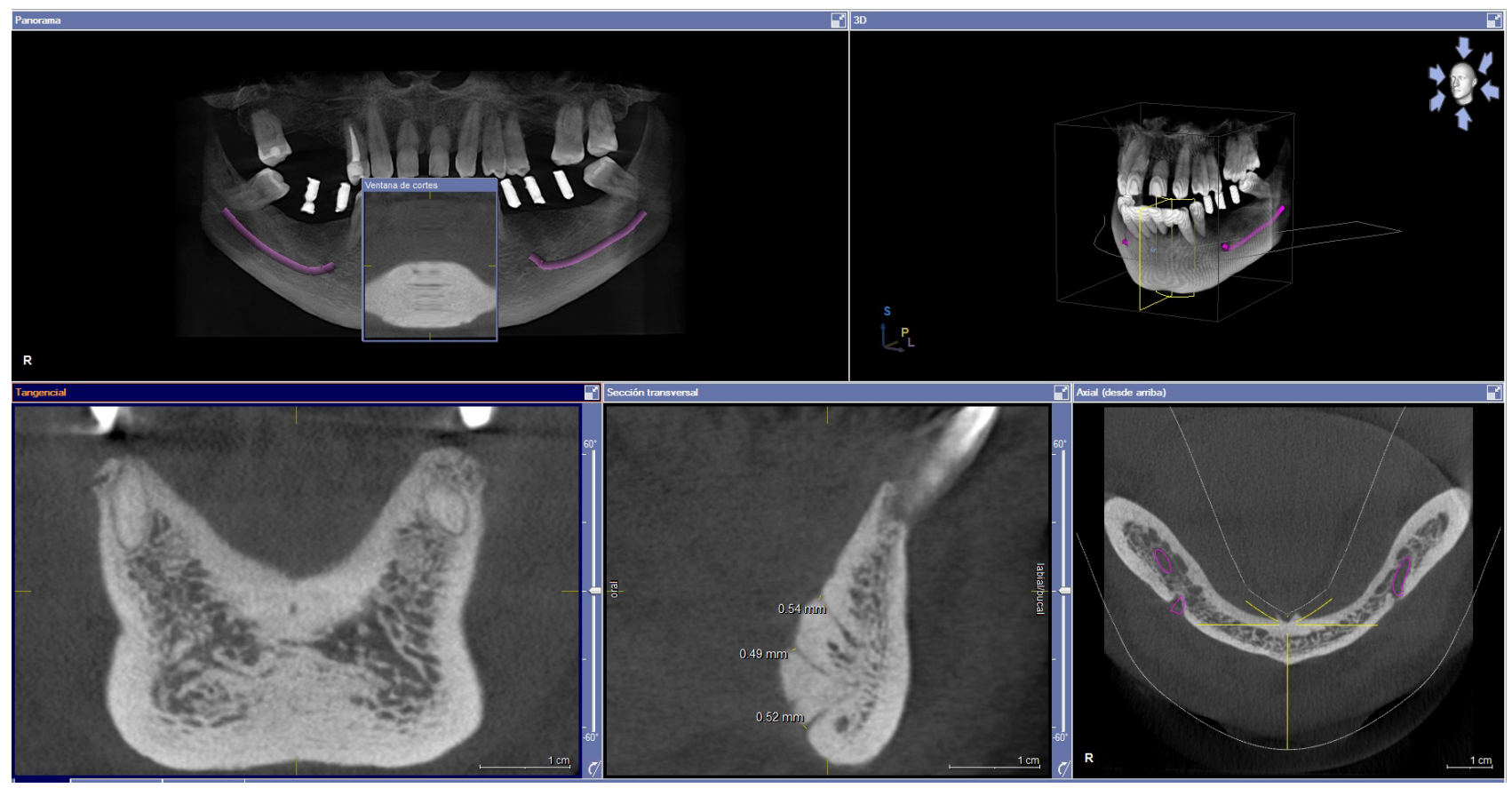

Figure 1: Monitor showing the panoramic view, the 3D reconstruction and transverse, tangential and axial views (from left to right and up to down) 
It was determined to use a sample size of 138 patients, statistically calculated, with a $90 \%$ of lingual foramina prevalence and an error of $5 \%$. The CBCT images were obtained by a radiology technician using an Orthophos XG (Sirona, Germany) equipment with a time of exposure of 14.2 seconds, $85 \mathrm{kV}$ and $7 \mathrm{~mA}$.

Distorted images or images with any visible flaw were excluded, as well as patients younger than 18 years of age, and radiographs that showed alterations corresponding to syndromes or anomalies.

To determine the presence and vertical diameter of the lingual foramina, transversal views were used. In order to measure the vertical diameter, one of the tools in the Galileos ${ }^{\circledR}$ software was used (Fig. 2), in which a line was drawn from the superior edge of each foramina down to the inferior edge.

For the lingual canals analysis, transversal views were mainly used, drawing a line from the entrance of the canal to its end, using another tool from the Galileos ${ }^{\circledR}$ software.

The sex variable and its relationship between amount, location and diameter of lingual foramina were investigated through the logistic regression model. The same was done using the age variable. The Odds Ratio (OR) was used as an association measure, with its corresponding confidence interval of $95 \%$. The association between sex and age with the presence of lingual foramina was examined through the Independence test $\mathrm{Chi}^{2}$ and the Spearman's correlation (r). All the statistical analysis was done using the Stata 12.1 software.

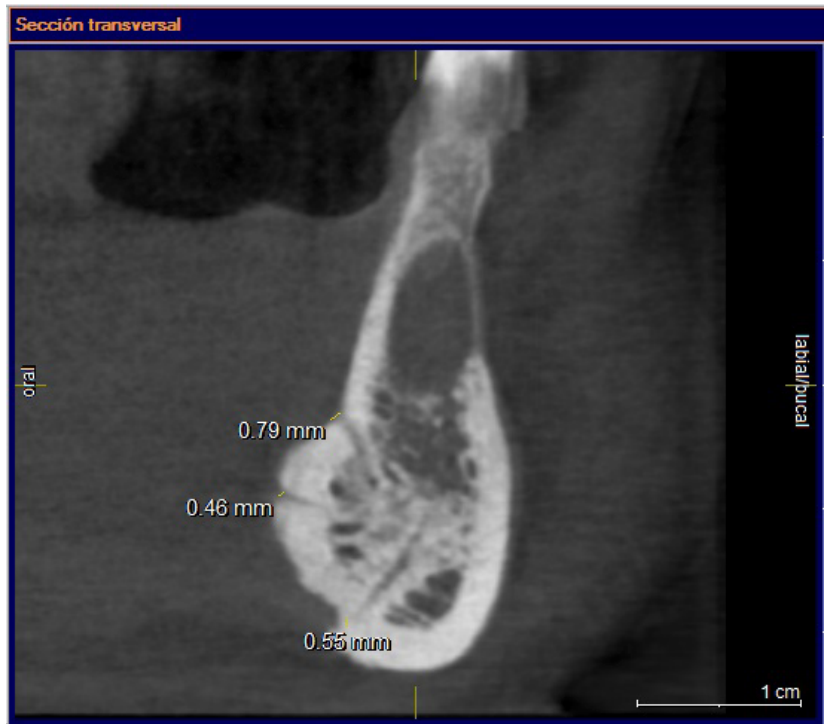

Fig. 2.Upper, middle and lower foramina and their respective measurements in the transverse view.
The CBCT exams that were studied were part of the patient's examination at the Universidad de Los Andes's Dentistry Clinic. Those exams were prescribed in the patient's best interest, complementary to their diagnosis and treatment planning. None of the patients studied were subject to any unnecessary radiation.

As a protocol of the clinic, the patient was required to sign an informed consent before being treated. This document states that the patients allow using their radiological exams as part of academic studies. Additionally, this research has been approved by the Ethics Committee of Universidad de los Andes.

\section{RESULTS}

The sample included a total of 183 patients; all of them were adults (over 18 years old). For the purpose of estimating percentages and calculating averages, it was decided that the median was going to be used in all calculations due the asymmetric distribution presented in the variables age and sex. The results can be seen in Table I.

Regarding to the sex, of 138 (100\%) patients, 95 $(69 \%)$ were female and $43(31 \%)$ were male. Also, 22 patients had one foramen, 69 had two foramina and 47 had three foramina. The presence of 2 lingual foramina was predominant.

The total number of foramina present in the 138 patients was 296. Out of this total, 97 were from male patients and 199 were from female patients. Regarding the location of the foramina related to mental spines the results are shown in Table II.

Regarding the foramina's vertical diameter, the results are shown in Table III.

As to the presence of the upper, middle and lower foramina, the results can be seen in Tables IV, V and VI respectively.

There was not a statistically significant relation between the presence of upper, middle and lower foramina and the sex of the patients, the results obtained are shown in Table VII.

The diameter of the upper, middle and lower foramina, on male and female patients, are shown in Table VIII and IX respectively. 
Table I. Analysis of the age variable.

\begin{tabular}{cccccc}
\hline Variable & Median & Iqr & Minimum Age & Maximum Age & Total \\
\hline Age & 51.64 & 20 & 20 & 83 & 138 \\
\hline IQR. interquartile range. & & & &
\end{tabular}

Table II. Foramina prevalence by sex.

\begin{tabular}{lccc}
\hline Variable & Males & Females & Total \\
\hline Upper Foramina & 41 & 92 & 133 \\
Middle Foramina & 17 & 26 & 43 \\
Lower Foramina & 39 & 81 & 120 \\
Total & 97 & 199 & 296 \\
\hline
\end{tabular}

Table III. Median for the upper, middle and lower foramina regarding its vertical diameter in millimeters $(\mathrm{mm})$ and total foramina.

\begin{tabular}{lccccc}
\hline Foramina & Median & Iqr & $\begin{array}{c}\text { Minimum } \\
\text { diameter }\end{array}$ & $\begin{array}{c}\text { Maximum } \\
\text { Diameter }\end{array}$ & Total (n) \\
\hline Upper & $0.76 \mathrm{~mm}$ & 0.27 & $0.45 \mathrm{~mm}$ & $1.24 \mathrm{~mm}$ & 133 \\
Middle & $0.52 \mathrm{~mm}$ & 0.11 & $0.29 \mathrm{~mm}$ & $0.9 \mathrm{~mm}$ & 43 \\
Lower & $0.55 \mathrm{~mm}$ & 0.2 & $0.21 \mathrm{~mm}$ & $1.24 \mathrm{~mm}$ & 120 \\
\hline
\end{tabular}

IQR. interquartile range

Table IV. Number of patients with or without upper foramina by sex.

\begin{tabular}{lccc}
\hline Upper foramina & Male & Female & Total \\
\hline Absent & $2(4.65 \%)$ & $3(3.16 \%)$ & $5(3.62 \%)$ \\
Present & $41(95.35 \%)$ & $92(96.84 \%)$ & $133(96.38 \%)$ \\
Total & $43(100 \%)$ & $95(100 \%)$ & $138(100 \%)$ \\
\hline
\end{tabular}

Table V. Amount of patients with or without middle foramina according to their sex.

\begin{tabular}{lccc}
\hline Middle foramina & Male & Female & Total \\
\hline Absent & $26(60.47 \%)$ & $71(74.74 \%)$ & $97(70.29 \%)$ \\
Present & $17(39.53 \%)$ & $24(25.26 \%)$ & $41(29.71 \%)$ \\
Total & $43(100 \%)$ & $95(100 \%)$ & $138(100 \%)$ \\
\hline
\end{tabular}

Table VI. Amount of patients with or without lower foramina according to their sex.

\begin{tabular}{lccc}
\hline $\begin{array}{l}\text { Lower } \\
\text { Foramina }\end{array}$ & Male & Female & Total \\
\hline Absent & $4(9.3 \%)$ & $14(14.74 \%)$ & $18(13.04 \%)$ \\
Present & $39(90.7 \%)$ & $81(85.26 \%)$ & $120(86.96 \%)$ \\
Total & $43(100 \%)$ & $95(100 \%)$ & $138(100 \%)$ \\
\hline
\end{tabular}

Table VII. Relation between foramina and sex.

\begin{tabular}{lccc}
\hline Variable & Odds ratio (or) & P-value & Confidence interval 95 \\
\hline Upper foramina & 1.49 & 0.66 & $0.24-9.29$ \\
Middle foramina & 0.51 & 0.09 & $0.24-1.11$ \\
Lower foramina & 0.59 & 0.38 & $0.18-1.92$ \\
\hline
\end{tabular}


Regarding the lingual canals, the average length can be best seen in the Table X. Table XI shows medians and the differences in the diameter between sexes.

It's also important to note that there are differences between the lengths of the lingual canals, being the male patients the ones that had longer lengths in the 3 types of canals.

Table VIII. Averages of vertical diameter for upper, medium and lower foramina on male patients.

\begin{tabular}{cccccc}
\hline Foramina & Median & Minimum & Maximum & Iqr & Total foramina \\
\hline Upper & $0.77 \mathrm{~mm}$ & $0.55 \mathrm{~mm}$ & $1.13 \mathrm{~mm}$ & 0.19 & 41 \\
Middle & $0.55 \mathrm{~mm}$ & $0.33 \mathrm{~mm}$ & $0.9 \mathrm{~mm}$ & 0.11 & 17 \\
Lower & $0.6 \mathrm{~mm}$ & $0.21 \mathrm{~mm}$ & $0.24 \mathrm{~mm}$ & 0.33 & 39 \\
\hline
\end{tabular}

IQR: interquartile range.

Table IX. Averages of vertical diameter for the upper, medium and lower foramina on female patients.

\begin{tabular}{llllcc}
\hline Foramina & Median & Minimum & Maximum & Iqr & Total foramina \\
\hline Upper & $0.76 \mathrm{~mm}$ & $0.45 \mathrm{~mm}$ & $1.24 \mathrm{~mm}$ & 0.3 & 96 \\
Middle & $0.5 \mathrm{~mm}$ & $0.29 \mathrm{~mm}$ & $0.71 \mathrm{~mm}$ & 0.11 & 26 \\
Lower & $0.53 \mathrm{~mm}$ & $0.32 \mathrm{~mm}$ & $1 \mathrm{~mm}$ & 0.16 & 81 \\
\hline
\end{tabular}

IQR: interquartile range.

Table X. Average length of upper, middle and lower lingual canals (millimeters).

\begin{tabular}{lccccc}
\hline Canals & Median & Minimum & Maximum & Iqr & $\begin{array}{c}\text { Total } \\
\text { Foramina }\end{array}$ \\
\hline Upper & $748 \mathrm{~mm}$ & $3.37 \mathrm{~mm}$ & $12.13 \mathrm{~mm}$ & 2.3 & 131 \\
Middle & $7.53 \mathrm{~mm}$ & $5.17 \mathrm{~mm}$ & $12.41 \mathrm{~mm}$ & 1.9 & 41 \\
Lower & $6.83 \mathrm{~mm}$ & $2.8 \mathrm{~mm}$ & $9.97 \mathrm{~mm}$ & 1.5 & 118 \\
\hline
\end{tabular}

IQR: interquartile range.

Table XI. Average length of upper, middle and lower lingual canals (millimeters) by sex.

\begin{tabular}{lcc}
\hline Variable & Male & Female \\
\hline Upper canal & $7.9 \mathrm{~mm}$ & $7.29 \mathrm{~mm}$ \\
Middle canal & $7.85 \mathrm{~mm}$ & $7.3 \mathrm{~mm}$ \\
Lower canal & $7.1 \mathrm{~mm}$ & $6.69 \mathrm{~mm}$ \\
\hline
\end{tabular}

\section{DISCUSSION}

The CBCT images allow the visualization of accessory mandibular canals with high resolution and precision. A deep understanding of the prevalence and distribution of accessory canals is an important clinical matter. Studies have shown a high prevalence of foramina, upper and lower, varying between $85 \%$ and $99 \%$ of general (Liang et al.; von Arx et al., 2011).
The prevalence of the upper lingual foramina in this study was $44 \%$ (133), of middle foramina was $16 \%$ (43) and for the lower foramina was $40 \%$ (120), from a total of 296 foramina. Similar results have been published, where 68 mandibles were analyzed through CBCT images. Out se 68 mandibles, lingual foramina were observed in 66 of them. The upper foramina were found in $59(87 \%)$, while the lower foramina were found in $57(84 \%)$, being slightly higher the prevalence of upper foramina, obtaining the same result as in our study (Kawai et al., 2007). It is important to note that in that study the middle foramina were not considered. In the upper foramina as in the lower foramina, there are blood vessels going through, suggesting that the sublingual artery is important in the irrigation of the mandible in the lingual midline.

As for the vertical diameter, the averages of the upper, middle and lower foramina were $0.76 \mathrm{~mm}, 0.52 \mathrm{~mm}$ and $0.55 \mathrm{~mm}$ respectively. These results are very much alike to the ones established in scientific literature: $1.16 \mathrm{~mm}$ (Sekerci et al., 2014) and between $0.90 \mathrm{~mm}$ and $1.01 \mathrm{~mm}$ (Liang et al.). On the other hand, the average vertical diameter of the largest upper and lower foramina was $1.12 \mathrm{~mm}$ for the upper and $0.9 \mathrm{~mm}$ for the lower (von Arx et al.).

In this study no statistically significant differences were found between the diameter of the upper, middle and lower foramina regarding the sex of the patients (p-value of 0.6 for the upper foramina, 0.09 for the middle foramina and 0.3 for the lower foramina). Neither a correlation between the diameter of the upper, middle and lower foramina and the age of the patients was found.

As it was mentioned before, these foramina contain a neurovascular bundle (an artery, vein and nerve). The lingual foramina close to the midline have a branch of the sublingual artery and/or the lingual artery. The foramina located on the posterior area (in the premolar area) have a branch of the sublingual and submental artery or an anastomosis of them (Vandewalle et al.2005; Babiuc et al., 2011).

Out of the 138 patients that were analyzed, there was a higher prevalence of patients that presented 2 lingual foramina (69 patients, $50 \%$ ), followed by the patients that presented 3 foramina (47 patients, $34.06 \%$ ), while patients 
with 1 foramen were the ones with the least prevalence $(22$ patients, $15.94 \%)$. On the contrary, in the scientific literature it has been established that the amount of foramina on patients was between 1 and 3 , with the following distribution; 1 foramen in $48 \%$ of the subjects, 2 foramina in $36.6 \%$ of the subjects and 3 in $10.6 \%$ of the subjects, being the highest prevalence patients with 1 foramen, followed by patients with 2 foramina. Regarding the length of the canals, there were significant differences between sexes the canals in male patients being longer than in female patients (in the 3 different canals), being the middle lingual canal the longest with a median of $7.53 \mathrm{~mm}$ (Sekerci et al.)

Tomography based techniques provide adequate information on the anatomy of the jaw, specifically in the area between foramina. Preoperative exams of the vital structures are essential for the safe installation of implants in the area between foramina, as well as planning for invasive procedures in this area. On the contrary, the diameter, shape and location of the lingual foramina and its canals must be investigated case by case since it varies between individuals (Yoshida et al. 2005; Rosano et al; Miller et al.)

\section{CONCLUSION}

There are no significant differences between sexes regarding the amount and size of lingual foramina, neither there were regarding the size and age of the patients. Additionally, the foramina located above the mental spines were predominant. Also, as to the amount of foramina, the higher prevalence observed was in patients with 2 lingual foramina.

The CBCT has been established as a powerful image diagnosis tool capable of providing depth information about the anatomic structures, enabling a detailed evaluation of its topography and anatomic variations between a subject to another.

SANHUEZA, A.; BRINER, M.; CALVO, M. \& CISTERNAS, A. Presencia en el CBCT de foraminas y canales linguales en pacientes mayores de 18 años de edad. Int. J. Morphol., 36(1):80-86, 2018.

RESUMEN: Las foraminas y canales linguales están localizados en la línea media mandibular, los cuales son relevantes dado a su componente neurovascular. Las foraminas linguales pueden ser clasificadas según su localización respecto a las espinas mentonianas pudiendo ser supraespinosas, interespinosas e infraespinosas. El objetivo del trabajo fue determinar la prevalencia, tamaño y relación anatómica de foraminas y canales linguales en pacientes mayores de 18 años de edad que hayan sido tratados en el centro odontológico de la Universidad de Los Andes, San Bernardo, Chile. Además establecer diferencias de sexo en cuanto a la presencia de foraminas linguales, ubicación y diámetro. Del total de la muestra, 296 foraminas fueron encontradas de las cuales $133(45 \%)$ eran supraespinosas, $43(15 \%)$ intraespinosas y 120 (40 \%) infraespinosas. En ambos sexos la prevalencia de las supraespinosas fue mayor. Respecto al diámetro vertical de las foraminas, la mediana de diámetro para la supraespinosa fue de $0,76 \mathrm{~mm}$, de la intraespinosa fue de $0,52 \mathrm{~mm}$ y de la infraespinosa fue de $0,55 \mathrm{~mm}$. Respecto a la longitud de los canales linguales, el canal intraespinoso fue el más largo $(7,48 \mathrm{~mm})$, seguido por el supraespinoso $(7,53 \mathrm{~mm})$ y finalmente el infraespinoso $(6,83 \mathrm{~mm})$. No había una diferencia estadísticamente significativa entre sexos respecto a la cantidad y tamaño de las foraminas linguales. Tampoco lo hubo respecto al diámetro de los canales y la edad de los pacientes. Sin embargo, si lo hubo respecto a la longitud de los canales, siendo los pacientes masculinos lo que presentaban los canales más largos. Debido a la alta prevalencia de las foraminas y canales linguales en la muestra es recomendado considerarles en los planes de tratamiento de procedimientos quirúrgicos en la línea media mandibular.

PALABRAS CLAVE: Tomografía computarizada haz de cono; Foramina lingual; Linea media mandibular.

\section{REFERENCES}

Babiuc, I.; Tarlungeanu, I. \& Pauna, M. Cone beam computed tomography observations of the lingual foramina and their bony canals in the median region of the mandible. Rom. J. Morphol. Embryol., 52(3):827-9, 2011.

Dreiseidler, T.; Mischkowski, R. A.; Neugebauer, J.; Ritter, L. \& Zöller, J. E. Comparison of cone-beam imaging with orthopantomography and computerized tomography for assessment in presurgical implant dentistry. Int. J. Oral Maxillofac. Implants, 24(2):216-25, 2009.

Kawai, T.; Asaumi, R.; Sato, I.; Yoshida, S. \& Yosue, T. Classification of the lingual foramina and their bony canals in the median region of the mandible: cone beam computed tomography observations of dry Japanese mandibles. Oral Radiol., 23(2):42-8, 2007.

Liang, X.; Jacobs, R.; Lambrichts, I.; Vandewalle, G.; van Oostveldt, D.; Schepers, E.; Adriaensens, P. \& Gelan, J. Microanatomical and histological assessment of the content of superior genial spinal foramen and its bony canal. Dentomaxillofac. Radiol., 34(6):362-8, 2005.

Miller, R. J.; Edwards, W. C.; Boudet, C. \& Cohen, J. H. Maxillofacial anatomy: the mandibular symphysis. J. Oral Implantol., 37(6):745-53, 2011.

Murlimanju, B. V.; Prakash, K. G.; Samiullah, D.; Prabhu, L. V.; Pai, M. M.; Vadgaonkar, R. \& Rai, R. Accessory neurovascular foramina on the lingual surface of mandible: Incidence, topography, and clinical implications. Indian J. Dent. Res., 23(3):433, 2012.

Patil, S.; Matsuda, Y. \& Okano, T. Accessory mandibular foramina: a CT study of 300 cases. Surg. Radiol. Anat., 35(4):323-30, 2013.

Rosano, G.; Taschieri, S.; Gaudy, J. F.; Testori, T. \& Del Fabbro, M. Anatomic assessment of the anterior mandible and relative hemorrhage risk in implant dentistry: a cadaveric study. Clin. Oral Implants Res., 20(8):791-5, 2009.

Sekerci, A. E.; Sisman, Y. \& Payveren, M. A. Evaluation of location and dimensions of mandibular lingual foramina using cone-beam computed tomography. Surg. Radiol. Anat., 36(9):24-30, 2014. 
SANHUEZA, A.; CALVO, M; CISTERNAS, A \& BRINER, M. The presence of foramina and lingual canal on CBCT on patients over 18 years of age. Int. J. Morphol., 36(1):80-86, 2018.

Soto, R.; Cáceres, F. \& García, R. Presence and morphometry of foramina and canals in relation to mental spines. Int. J. Morphol., 30(2):417-21, 2012.

Tagaya, A.; Matsuda, Y.; Nakajima, K.; Seki, K. \& Okano, T. Assessment of the blood supply to the lingual surface of the mandible for reduction of bleeding during implant surgery. Clin. Oral Implants Res., 20(4):3515,2009

Vandewalle, G.; Liang, X.; Jacobs, R. \& Lambrichts, I. Macroanatomic and radiologic characteristics of the superior genial spinal foramen and its bony canal. Int. J. Oral Maxillofac. Implants, 21(4):581-6, 2005.

von Arx, T.; Matter, D.; Buser, D. \& Bornstein, M. M. Evaluation of location and dimensions of lingual foramina using limited cone-beam computed tomography. J. Oral Maxillofac. Surg., 69(11):2777-85, 2011.

Yoshida, S.; Kawai, T.; Okutsu, K.; Yosue, T.; Takamori, H.; Sunohara, M. $\&$ Sato, I. The appearance of foramen in the internal aspect of the mental region of mandible from Japanese cadavers and dry skulls under macroscopic observation and three-dimensional CT images. Okajimas Folia Anat. Jpn., 82(3):83-7, 2005.

\author{
Corresponding author: \\ Michelle Briner \\ General Dentist \\ Universidad de Los Andes \\ Santiago \\ CHILE
}

Email: michellebrinergarrido@gmail.com

Received: 03-05-2017

Accepted: 11-10-2017 